\title{
Effects of Styrene-metabolizing Enzyme Polymorphisms and Lifestyle Behaviors on Blood Styrene and Urinary Metabolite Levels in Workers Chronically Exposed to Styrene
}

\author{
Ki-Woong Kim \\ Occupational Safety and Health Research Institute, KOSHA, Ulsan, Korea
}

(Received July 28, 2015; Revised August 24, 2015; Accepted August 31, 2015)

\begin{abstract}
The aim of this study was to investigate whether genetic polymorphisms of CYP2E1, GSTM1, and GSTT1 and lifestyle habits (smoking, drinking, and exercise) modulate the levels of urinary styrene metabolites such as mandelic acid (MA) and phenylglyoxylic acid (PGA) after occupational exposure to styrene. We recruited 79 male workers who had received chronic exposure in styrene fiberglass-reinforced plastic manufacturing factories. We found that serum albumin was significantly correlated with blood styrene/ambient styrene (BS/AS), urinary styrene (US)/AS, and US/BS ratios as well as urinary metabolites, that total protein correlated with US/MA and US/PGA ratios, and that low density lipoprotein (LDL)-cholesterol significantly correlated with US/BS, US/MA, and US/PGA ratios. Multiple logistic regression analyses using styrene-metabolizing enzyme genotypes and lifestyle habits as dependent variables and blood and urine styrene concentrations and urine styrene metabolite levels as independent variables revealed that CYP2E1*5 was associated with the MA/US ratio and GSTM1 with US/BS, that a smoking habit was associated with US/AS and MA/US ratios and MA and PGA levels, and that regular exercise was correlated with PGA/US. In conclusion, the results suggested that genetic polymorphisms of styrene-metabolizing enzymes, lifestyle behaviors, and albumin and LDL-cholesterol serving as homeostasis factors together are involved in styrene metabolism.
\end{abstract}

Key words: Styrene, Metabolism, Gene polymorphisms, Biological monitoring, Workers

\section{INTRODUCTION}

Styrene (CAS No. 100-42-5) is a monocyclic aromatic hydrocarbon material that is used widely during the production of synthetic rubber, polyester resin, and fiberglass-reinforced plastic (1). Over 25,980 workers exposed to styrene according to a 2013 report of occupational health examination (2). Styrene is rapidly absorbed via the lung and through skin contact and is primarily metabolized in the liver, with a minor contribution from extrahepatic organs (1). The first step in the detoxification process is oxidation of styrene to styrene 7,8-oxide (SO) by cytochrome P-450

\footnotetext{
Correspondence to: Ki-Woong Kim, Occupational Safety and Health Research Institute, KOSHA, Ulsan 681-230, Korea E-mail: k0810@kosha.net

This is an Open-Access article distributed under the terms of the Creative Commons Attribution Non-Commercial License (http:// creativecommons.org/licenses/by-nc/3.0) which permits unrestricted non-commercial use, distribution, and reproduction in any medium, provided the original work is properly cited.
}

enzymes (CYPs) including the CYP2E1 and CYP2B isozymes (3). SO is mainly hydrolyzed to styrene glycol by microsomal epoxide hydrolase, which is in turn subsequently oxidized by additional enzymes to generate its primary metabolites such as mandelic acid (MA) and phenylglyoxylic acid (PGA) that are excreted with the urine (4). The metabolic rate of styrene is regulated at the oxidation step by CYP2E1, and toxicity is generally induced by the production of activated metabolic intermediates such as SO during styrene metabolic processing (5). The primary target for styrene toxicity appears to be the nervous system; symptoms of neurological disorders involving both the central and peripheral nervous systems have been reported in workers exposed to styrene (6). Although the exact mechanism of styrene-induced neurotoxicity remains unknown, associations have been identified with both dopaminergic and serotoninergic systems (7). In addition, Jenkins and Fennell (8) have reported that styrene and SO are not only neurotoxic but are carcinogenic and genotoxic as well.

Biological monitoring of styrene exposure is achieved by measuring the urinary metabolites MA and PGA at the end 
of the work shift and/or prior to the next shift (9); however, individual differences in urinary metabolites have been observed (10). Urinary metabolite concentrations have been associated with genetic polymorphism of styrene-metabolizing enzymes such as CYP2E1, microsomal epoxide hydrolase, glutathione-S-transferase (GST) M1, and GSTT1 $(11,12)$.

Haufroid et al. (13) have reported the excretion amount of urinary MA and PGA associated with genetic polymorphisms of CYP2E1 and urinary phenyl hydroxyethyl mercapturic acids as minor metabolite of styrene was associated with GSTs polymorphisms (14), but research data for association between GSTs polymorphisms and urinary metabolites of styrene is scarce.

Ma et al. (15) reported that neither genetic polymorphism of CYP2E1, CYP2B6, GSTM1, and GSTT1 nor smoking habit. In particular, smoking was shown inhibit the metabolism of styrene by changing CYP activity. Comparatively, Coccini et al. (16) reported that the levels of CYP and cytochrome $b_{5}$ as well as the activity of CYP-dependent aniline hydroxylase in subjects treated with a combination of styrene and ethanol were significantly increased compared with those in the styrene single treatment group, and that the concentrations of MA and PGA were significantly increased in the combined-treatment group as well. These findings were explained by the suggestion that the increase of urinary MA and PGA levels in the combinedtreatment group resulted from an enhanced induction of CYP by ethanol, which in turn contributed to styrene metabolism leading to elevated metabolite release. However, the influences of genetic polymorphism of styrenemetabolizing enzymes and of lifestyle behaviors (i.e., smoking, drinking, and exercise) on the outcome measures of styrene metabolism is not clear. Furthermore, despite continued progress from the pharmacokinetic and pharmacodynamic study of styrene metabolism, there has been no clear conclusion regarding the relationship between styrene absorption, genetic polymorphism of styrene-metabolizing enzymes, and lifestyle behaviors. Accordingly, the aim of the present study was to investigate whether the genetic polymorphisms of CYP2E1, GSTM1, and GSTT1 and the lifestyle habits smoking, drinking, and exercise modulate the levels of urinary styrene metabolites such as MA and PGA after occupational exposure to styrene.

\section{MATERIALS AND METHODS}

Study subjects. The study subjects consisted of 79 men who had been chronically exposed to styrene in fiberglassreinforced plastic manufacturing factories. The authors visited the selected factories and carefully explained the objectives and experimental methods of the study as well as the privacy policy directives and other related matters to the workers, and each worker enrolled in the study provided his informed consent. The health status of each subject was assessed by interview, and their lifestyle habits and general characteristics were surveyed using a self-reported questionnaire. This study was approved by the Institutional Review Board of the Occupational Safety and Health Research Institute, Korea Occupational Safety and Health Agency.

Ambient styrene and biological monitoring. Ambient styrene in the workplace was sampled using a low volume active sampler (Gilian Low Flow Sampler 113 D, Sensidyne, Inc., Clearwater, FL, USA) and analyzed according to "Method 1501: Aromatic Hydrocarbons" as recommended by the National Institute for Occupational Safety and Health (17). Venous blood samples were collected in tubes containing $7.2 \mathrm{mg} \mathrm{K}_{2}$ EDTA and subject urine was collected in high density polyethylene bottles at the end of the work shift; samples were stored at $4^{\circ} \mathrm{C}$ until analysis. To analyze the concentration of blood styrene, $1 \mathrm{~mL}$ blood was collected from each subject and placed in a 20 -mL headspace injection vial. The stopper was immediately replaced and a gas chromatograph/mass selective detector with a headspace sampler (Hewlett-Packard 7694 headspace sampler/6890 GC/5793 Mass Selective Detector, Agilent Technologies, Santa Clara, CA, USA) was used for the determination according to Kim et al. (18). The concentration of urinary styrene was also determined with this system according to Kim et al. (18). Urinary styrene metabolites such as MA and PGA were analyzed using a gas chromatograph (CP-3800 GC/FID, Varian Ltd., USA) according to the method described by de Carvalho et al. (19).

Measurements of anthropometric parameters and serum biochemistry. Body mass index and body fat percentage were measured using a body composition analyzer (X-SCAN plus II, Jawon Medical, SEOUL, Korea). Subcutaneous and visceral fat thicknesses were measured with ultrasonic diagnostic equipment (SonoAce 8800, Madison, Seoul, Korea) using a B-mode ultrasound $3.5 \mathrm{MHz}$ oval probe. Serum biochemistry including albumin, total protein, alkaline phosphatase, alanine aminotransferase, aspartate aminotransferase, gamma-glutamyl transferase, total cholesterol, high- and low-density lipoprotein-cholesterol, and triglyceride was performed using an automatic biochemistry analyzer (COBAS Integra 400, Roche Diagnostics Ltd., Rotkreuz, Switzerland).

Genetic polymorphisms of CYP2E1, GSTM1, and GSTT1. Genomic DNA was extracted from collected blood using the QIAamp ${ }^{\mathrm{r}} \mathrm{DNA}$ Mini Kit (QIAGEN, Hilden, Germany) according to standard procedures recommended in the QIAamp DNA Blood Mini Kit handbook. The genetic variants in GSTM1 and GSTT1 were analyzed using the method of Shaikh et al. (20) with slight modifica- 
tions. A total of $10 \mathrm{pM}$ each of the GSTMI (sense, 5'-GAA CTC CCT GAA AAG CTA AAG-3' and anti-sense, 5'GTT GGG CTC AAA TAT ACG GTG G-3') and GSTT1 (sense, 5'-TTC CTT ACT GGT CCT CAC ATC TC-3' and anti-sense, 5'-TCA CCG GAT CAT GGC CAG CA-3') primers were added to $1 \mu \mathrm{L}$ genomic DNA extracted from the blood samples, and then mixed with AccuPowerTM PCR premix (Bioneer Co., Korea) containing $10 \mathrm{mM}$ Tris$\mathrm{HCl}$ (pH 9.0), $40 \mathrm{mM} \mathrm{KCl}, 1.5 \mathrm{mM} \mathrm{MgCl} 2,1 \mathrm{U}$ DNA polymerase, and $1 \mathrm{mM}$ dNTPs. The total volume was then made up to $20 \mu \mathrm{L}$ with triple-distilled water prior to amplification (iCycler, Bio-Rad Laboratories, Inc., Hercules, CA, USA). The amplified product was subjected to electrophoresis on a $1.5 \%$ agarose gel, and the polymorphic variant was determined by checking for the presence of bands at 210 and $473 \mathrm{bp}$. The primers used in the CYP2E1*5 polymorphism analysis (sense, 5'-CCA GTC GAG TCT ACA TTG TCA- $3^{\prime}$ and anti-sense, $5^{\prime}$-AGA CCT CCA CAT TGA CTA GC-3') were constructed according to the method of Cai et al. (21), and analyzed using the method of PrietoCastello et al. (22) with slight changes. After mixing $10 \mathrm{mM}$ Tris- $\mathrm{HCl}$ (pH 9.0), $40 \mathrm{mM} \mathrm{KCl}, 1.5 \mathrm{mM} \mathrm{MgCl}$, $1 \mathrm{U}$ DNA polymerase, $10 \mathrm{pM}$ primers, and $1 \mu \mathrm{L}$ genomic DNA the total volume was made up to $20 \mu \mathrm{L}$ with tripledistilled water, followed by iCycler amplification. After digestion of the amplicons using the Pst $\mathrm{I}$ restriction enzyme, electrophoresis was performed on a $2.0 \%$ agarose gel and the gene alleles were confirmed.

Statistical analysis. Statistical analysis for all data was performed using SPSS software (version 18.0, SPSS Inc., Chicago, IL, USA). The Pearson's correlation coefficient was used for correlations between each set of variables and multiple logistic regression analysis was performed for estimating the odds ratios of styrene metabolites with the tested variables (genetic and lifestyle parameters).

\section{RESULTS}

General subject characteristics and levels of anthropometric and clinical parameters. As shown in Table 1, the mean subject age was $38.1 \pm 9.9$ years, the mean number of working hours was $6.6 \pm 3.3$, and smokers and drinkers constituted $35(44.3 \%)$ and 37 (46.4\%) subjects, respectively. The mean exposure level of styrene was $25.2 \pm$ $38.8 \mathrm{ppm}$, and the concentrations of blood and urinary styrene were $828.9 \pm 1,183.0$ and $311.4 \pm 549.3 \mathrm{mg} / \mathrm{L}$ and the concentrations of MA and PGA were $0.36 \pm 0.42$ and 0.17 $\pm 0.14 \mathrm{~g} / \mathrm{g}$ creatinine, respectively. However, the mean concentrations of blood and urinary styrene in controls who had never been occupationally exposed to hazardous chemicals including styrene were $52.1 \pm 9.6$ and $12.1 \pm 7.3 \mathrm{mg} / \mathrm{L}$; the level of MA was $0.01 \mathrm{~g} / \mathrm{g}$ creatinine, and PGA was not detected. The levels of anthropometric and clinical parame-
Table 1. Characteristics of the study subjects

\begin{tabular}{lcc}
\hline \hline Variables & $\begin{array}{c}\text { Subjects } \\
(\mathrm{n}=79)\end{array}$ & $\begin{array}{c}\text { Control } \\
(\mathrm{n}=23)\end{array}$ \\
\hline Age (years) & $38.1 \pm 9.9$ & $37.8 \pm 10.0$ \\
Smoking, $\mathrm{n}(\%)$ & $35(44.3)$ & $10(43.5)$ \\
Cigarettes (per day) & $14.4 \pm 6.8$ & $12.9 \pm 7.2$ \\
Drinking & $37(46.4)$ & $10(43.5)$ \\
Alcohol $(\mathrm{g} /$ week$)$ & $87.3 \pm 113.0$ & $81.8 \pm 109.8$ \\
Regular exercise, $\mathrm{n}(\%)$ & $27(34.2)$ & $9(39.1)$ \\
Working hours (per day) & $6.6 \pm 3.3$ & $7.3 \pm 5.0$ \\
Ambient styrene $(\mathrm{ppm})$ & $25.2 \pm 38.8$ & - \\
Blood styrene $(\mu \mathrm{g} / \mathrm{L})$ & $828.9 \pm 1,183.0$ & $52.1 \pm 9.6$ \\
Urinary styrene $(\mu \mathrm{g} / \mathrm{L})$ & $311.4 \pm 549.3$ & $12.1 \pm 7.3$ \\
MA (g/g creatinine) & $0.36 \pm 0.42$ & $0.01 \pm 0.03$ \\
PGA (g/g creatinine) & $0.17 \pm 0.14$ & - \\
MA + PGA (g/g creatinine) & $0.53 \pm 0.55$ & - \\
\hline
\end{tabular}

MA, mandelic acid; PGA, phenylglyoxilic acid.

Table 2. Anthropometric and clinical parameters of study subjects

\begin{tabular}{lcc}
\hline \hline Variables & $\begin{array}{c}\text { Subjects } \\
(\mathrm{n}=79)\end{array}$ & $\begin{array}{c}\text { Reference } \\
\text { values }\end{array}$ \\
\hline Anthropometric parameters & & \\
Height (cm) & $167.4 \pm 6.8$ & - \\
Weight (kg) & $66.5 \pm 11.8$ & - \\
Body mass index (kg/m $\left.{ }^{2}\right)$ & $23.7 \pm 3.4$ & - \\
Body fat \% & $21.7 \pm 5.8$ & - \\
Subcutaneous fat thickness (cm) & $1.37 \pm 0.71$ & - \\
Visceral fat thickness (cm) & $3.82 \pm 1.34$ & - \\
Clinical parameters & & \\
Total protein (g/dL) & $6.67 \pm 0.53$ & $6.3-8.3$ \\
Albumin (g/dL) & $4.73 \pm 0.33$ & $3.5-5.0$ \\
Alkaline phosphatase (IU/L) & $67.8 \pm 18.8$ & $45-122$ \\
Alanine aminotransferase (IU/L) & $24.8 \pm 24.2$ & $10-44$ \\
Aspartate aminotransferase (IU/L) & $22.8 \pm 12.4$ & $10-34$ \\
Gamma-glutamyl transferase (IU/L) & $35.5 \pm 38.8$ & $7-50$ \\
Glucose (mg/dL) & $104.2 \pm 31.2$ & $70-105$ \\
Triglyceride (mg/dL) & $174.6 \pm 166.3$ & $40-160$ \\
Total cholesterol (mg/dL) & $182.0 \pm 33.7$ & $110-220$ \\
HDL-cholesterol (mg/dL) & $49.3 \pm 16.8$ & $42-74$ \\
LDL-cholesterol (mg/dL) & $106.8 \pm 35.2$ & $\leq 140$ \\
\hline
\end{tabular}

ters are shown in Table 2. The subject anthropometric mean values were: height 167.4 , weight $66.5 \mathrm{~kg}$, body mass index $23.7 \mathrm{~kg} / \mathrm{m}^{2}$, and body fat $\% 21.7$. The subcutaneous and visceral fat thicknesses were 1.37 and $3.82 \mathrm{~cm}$, respectively. The measurement results for the clinical parameters showed that mean concentration of total protein was $6.67 \mathrm{~g} / \mathrm{dL}$, albumin $4.73 \mathrm{~g} / \mathrm{dL}$, alkaline phosphatase $67.8 \mathrm{IU} / \mathrm{L}$, alanine aminotransferase $24.8 \mathrm{IU} / \mathrm{L}$, aspartate aminotransferase $22.8 \mathrm{IU} / \mathrm{L}$, gamma-glutamyl transferase $35.5 \mathrm{IU} / \mathrm{L}$, glucose $104.2 \mathrm{mg} / \mathrm{dL}$, triglyceride $174.6 \mathrm{mg} / \mathrm{dL}$, total cholesterol $182.0 \mathrm{mg} / \mathrm{dL}$, and of high- and low-density lipoprotein-cholesterol were 49.3 and $106.8 \mathrm{mg} / \mathrm{dL}$, respectively (Table 2). 
Table 3. Allelic frequencies in the study subjects

\begin{tabular}{cc}
\hline \hline Genotypes & Number (\%) \\
\hline CYP2E1*5 & \\
c1/c1 & $53(67.1)$ \\
c1/c2 & $26(32.9)$ \\
GSTM1 & \\
Positive & $34(43.0)$ \\
Null & $45(57.0)$ \\
GSTT1 & \\
Positive & $42(53.2)$ \\
Null & $37(46.8)$ \\
\hline
\end{tabular}

Genetic polymorphism study of CYP2E1 *5 and GSTM1 and GSTT1 variants. The results of genetic polymorphism analysis of CYP2E1*5 and variants in GSTM1 and GSTT1 are shown in Table 3. The allele frequencies for CYP2E1*5 $\mathrm{c} 1 / \mathrm{c} 1$ and $\mathrm{c} 1 / \mathrm{c} 2$ were 0.67 and 0.33 , respectively. The allele frequencies of GSTM1 positive and null variants were 0.43 and 0.57 , and of GSTT1 positive and null variants were 0.53 and 0.47 , respectively.
Correlations between lifestyle habits, anthropometric and clinical parameters, and genetic polymorphisms and styrene metabolism. The results from the correlation analyses between genetic polymorphisms of styrenemetabolizing enzymes and lifestyle habits and styrene metabolism are shown in Table 4. Height $(\mathrm{r}=0.463, p<$ $0.01)$ and weight $(r=0.294, p<0.05)$ showed positive correlation with the urinary styrene/blood styrene ratio (US/ BS), but height showed negative correlation with the US/ MA ratio $(\mathrm{r}=-0.449, p<0.01)$. As shown in Table 5, albumin was significantly correlated with the BS/ambient styrene (AS) ratio $(\mathrm{r}=-0.326, p<0.05), \mathrm{US} / \mathrm{AS}(\mathrm{r}=-0.318$, $p<0.05)$, US/BS $(\mathrm{r}=0.301, p<0.05)$, AS/MA $(\mathrm{r}=-0.328$, $p<0.05)$, AS/PGA $(\mathrm{r}=-0.329, p<0.05)$ US/MA $(\mathrm{r}=$ $-0.382, p<0.01)$, and US/PGA $(\mathrm{r}=-0.299, p<0.05)$. Total protein was significantly correlated with US/BS $(\mathrm{r}=0.311$, $p<0.05)$, US/MA ( $\mathrm{r}=-0.346, p<0.05)$, and US/PGA ( $\mathrm{r}=$ $-0.336, p<0.05)$, and low-density lipoprotein-cholesterol showed a correlation with US/BS $(\mathrm{r}=0.372, p<0.01)$, US/ MA $(\mathrm{r}=-0.515, p<0.01)$, and US/PGA $(\mathrm{r}=-0.443, p<$ $0.01)$. The excretion levels of urinary metabolites were

Table 4. Correlation coefficients between life habit and anthropometric parameters with styrene metabolites

\begin{tabular}{lrrrrrrr}
\hline \hline Variables & BS/AS & US/AS & US/BS & AS/MA & AS/PGA & US/MA & US/PGA \\
\hline Age & 0.227 & 0.218 & -0.077 & 0.233 & 0.231 & -0.044 & 0.017 \\
Height & -0.080 & -0.066 & 0.463 & -0.017 & -0.017 & -0.449 & -0.187 \\
Weight & -0.052 & -0.034 & 0.294 & -0.054 & -0.050 & -0.339 & -0.208 \\
BMI & -0.021 & -0.008 & 0.139 & -0.070 & -0.068 & -0.214 & -0.176 \\
Body fat \% & -0.162 & -0.156 & 0.024 & -0.195 & -0.195 & -0.041 & -0.011 \\
SFT & -0.273 & 0.095 & 0.333 & 0.158 & -0.296 & 0.110 & -0.254 \\
VFT & 0.054 & 0.047 & 0.141 & 0.058 & 0.026 & 0.031 & -0.137 \\
Exercise & -0.033 & -0.151 & -0.101 & -0.032 & 0.031 & 0.051 & 0.242 \\
Cigarettes & 0.128 & 0.124 & -0.395 & -0.453 & 0.589 & 0.496 & -0.147 \\
Alcohol & 0.324 & 0.172 & 0.049 & -0.274 & 0.244 & -0.016 & 0.085 \\
\hline AS, ambir
\end{tabular}

AS, ambient styrene; BS, blood styrene; US, urinary styrene; MA, mandelic acid; PGA, phenylglyoxylic acid; BMI, body mass index; SFT, subcutaneous fat thickness; VFT, visceral fat thickness.

Table 5. Correlation coefficients between serum biochemistry and styrene metabolites

\begin{tabular}{|c|c|c|c|c|c|c|c|}
\hline Variables & $\mathrm{BS} / \mathrm{AS}$ & US/AS & US/BS & AS/MA & AS/PGA & US/MA & US/PGA \\
\hline Albumin & $-0.326^{*}$ & $-0.318^{*}$ & $0.301 *$ & $-0.328 *$ & $-0.329 *$ & $-0.382 * *$ & $-0.299 *$ \\
\hline Total pro. & -0.258 & -0.249 & $0.311 *$ & -0.257 & -0.261 & $-0.346^{*}$ & $-0.336^{*}$ \\
\hline ALP & -0.084 & -0.078 & 0.165 & -0.082 & -0.084 & -0.022 & -0.056 \\
\hline ALT & -0.008 & 0.015 & 0.244 & -0.008 & -0.005 & -0.169 & -0.142 \\
\hline AST & 0.025 & 0.044 & 0.209 & 0.024 & 0.027 & -0.110 & -0.078 \\
\hline GGT & 0.060 & 0.073 & 0.144 & 0.060 & 0.062 & -0.150 & -0.152 \\
\hline Glucose & -0.138 & -0.136 & -0.128 & -0.139 & -0.141 & 0.179 & 0.016 \\
\hline Total chol. & -0.180 & -0.174 & 0.124 & -0.180 & -0.179 & -0.171 & -0.198 \\
\hline HDL-chol. & -0.057 & -0.065 & -0.044 & -0.055 & -0.055 & 0.074 & 0.066 \\
\hline LDL-chol. & -0.076 & -0.062 & $0.372 * *$ & -0.075 & -0.074 & $-0.515^{* *}$ & $-0.443^{* *}$ \\
\hline Triglyceride & -0.077 & -0.080 & -0.239 & -0.078 & -0.080 & $0.312^{*}$ & 0.198 \\
\hline
\end{tabular}

${ }^{* *} p<0.01 ;{ }^{*} p<0.05$; AS, ambient styrene; BS, blood styrene; US, urinary styrene; MA, mandelic acid; PGA, phenylglyoxylic acid; ALP, alkaline phosphatase; ALT, alanine aminotransferase; AST, aspartate aminotransferase; GGT, gamma-glutamyl transferase; Total chol., total cholesterol; HDL-chol., HDL-cholesterol, LDL-chol., LDL-cholesterol. 
Table 6. Influences of genetic polymorphisms of styrenemetabolizing enzymes on urinary metabolites

\begin{tabular}{ccccc}
\hline \hline Genotypes & US/AS & US/BS & US/MA & US/PGA \\
\hline CYP2E1*5 & & & & \\
c1/c1 & $22.4 \pm 35.7$ & $74.3 \pm 83.6$ & $0.58 \pm 1.29$ & $0.22 \pm 0.38$ \\
c1/c2 & $35.4 \pm 63.5$ & $69.3 \pm 97.5$ & $0.24 \pm 0.44$ & $0.15 \pm 0.24$ \\
p-value & 0.348 & 0.185 & 0.083 & 0.326 \\
\hline GSTM1 & & & & \\
Positive & $55.4 \pm 80.0$ & $98.9 \pm 102.7$ & $0.36 \pm 0.69$ & $0.22 \pm 0.36$ \\
Null & $29.9 \pm 44.7$ & $52.5 \pm 68.7$ & $0.33 \pm 0.98$ & $0.11 \pm 0.13$ \\
p-value & 0.426 & 0.019 & 0.878 & 0.090 \\
\hline GSTT1 & \multicolumn{5}{c}{} \\
Positive & $74.7 \pm 92.5$ & $84.8 \pm 102.3$ & $0.43 \pm 1.1$ & $0.18 \pm 0.27$ \\
Null & $33.9 \pm 46.3$ & $62.2 \pm 72.6$ & $0.27 \pm 0.5$ & $0.16 \pm 0.32$ \\
p-value & 0.306 & 0.258 & 0.397 & 0.830 \\
\hline
\end{tabular}

AS, ambient styrene; $B S$, blood styrene; US, urinary styrene; MA, mandelic acid; PGA, phenylglyoxylic acid.

lower in men carrying heterozygous CYP2E1*5 alleles and null forms of GSTM1 and GSTT1 in comparisons to those with the wild-type CYP2E1*5 and active forms of GSTM1 and GSTT1, but it was only significant for the US/BS ratio $(p=0.019)$ (Table 6). Accordingly, we then performed multiple logistic regression analysis with the genetic polymorphisms and lifestyle habits as dependent variables and US/
AS, BS/AS, US/BS, MA, PGA, MA/US, and PGA/US ratios as independent variables (Table 7). Among the genetic polymorphisms, GSTM1 was associated with US/BS (odds ratio $=0.993, \beta$ value $=-0.007, p=0.030)$ and $\mathrm{CYP} 2 \mathrm{E} 1 * 5$ was significantly associated with $\mathrm{MA} / \mathrm{US}$ (odds ratio = $0.472, \beta$ value $=-0.751, p=0.002$ ). Among the lifestyle behaviors, smoking was significantly associated with US/ $\mathrm{AS}$ (odds ratio $=1.015, \beta$ value $=0.014, p=0.010$ ), MA $($ odds ratio $=4.111, \beta$ value $=1.414, p=0.045)$, PGA (odds ratio $=5.778, \beta$ value $=4.057, p=0.023)$, and $\mathrm{MA} / \mathrm{US}$ (odds ratio $=8.716, \beta$ value $=4.468, p=0.017$ ). Regular exercise was significantly associated with PGA/US (odds ratio $=0.078, \beta$ value $=-2.551, p=0.047$ ), but drinking was not associated with any independent variable.

\section{DISCUSSION}

The factors that influence the styrene metabolic rate have not yet been elucidated. This is likely because individual differences exist at the physiological level including in homeostasis factors and in genetic polymorphisms influencing the levels and/or function of xenobiotic metabolizing enzymes, and lifestyle habits that can influence these in turn. Therefore, this study attempted to investigate whether genetic polymorphisms of CYP2E1, GSTM1, and GSTT1 and lifestyle behaviors including smoking, drinking, and

Table 7. Interrelationship between genetic polymorphisms of styrene-metabolizing enzymes and life habit with metabolites of styrene using multiple logistic regression analysis

\begin{tabular}{|c|c|c|c|c|c|c|c|c|c|c|c|c|}
\hline \multirow{4}{*}{$\begin{array}{l}\text { Independent } \\
\text { variables }\end{array}$} & \multicolumn{12}{|c|}{ Dependent variables } \\
\hline & \multicolumn{12}{|c|}{ Gene } \\
\hline & \multicolumn{4}{|c|}{ GSTM1 } & \multicolumn{4}{|c|}{ GSTT1 } & \multicolumn{4}{|c|}{ CYP2E5 } \\
\hline & $\beta$ value & S.E. & OR & $\mathrm{p}$ value & $\beta$ value & S.E. & OR & $\mathrm{p}$ value & $\beta$ value & S.E. & OR & $\mathrm{p}$ value \\
\hline US/AS ratio & 0.001 & 0.001 & 1.001 & 0.529 & -0.038 & 0.025 & 0.962 & 0.131 & 0.004 & 0.014 & 1.004 & 0.782 \\
\hline $\mathrm{BS} / \mathrm{AS}$ ratio & 0.002 & 0.006 & 1.002 & 0.779 & -0.007 & 0.014 & 0.993 & 0.645 & -0.001 & 0.004 & 0.999 & 0.868 \\
\hline US/BS ratio & -0.007 & 0.003 & 0.993 & 0.030 & 0.014 & 0.008 & 1.014 & 0.074 & 0.000 & 0.006 & 1.000 & 0.998 \\
\hline MA & -0.147 & 0.542 & 0.863 & 0.786 & 0.033 & 2.505 & 1.033 & 0.990 & -1.251 & 2.322 & 0.286 & 0.590 \\
\hline PGA & 1.008 & 1.626 & 2.741 & 0.535 & -1.882 & 1.654 & 0.152 & 0.255 & 0.335 & 1.718 & 1.398 & 0.845 \\
\hline MA/US ratio & 0.044 & 0.283 & 1.045 & 0.876 & 0.968 & 5.777 & 2.633 & 0.867 & -0.751 & 0.243 & 0.472 & 0.002 \\
\hline \multirow[t]{4}{*}{ PGA/US ratio } & 2.157 & 1.446 & 8.643 & 0.136 & -0.174 & 0.799 & 0.840 & 0.827 & 0.775 & 0.810 & 2.170 & 0.339 \\
\hline & \multicolumn{12}{|c|}{ Life habit } \\
\hline & \multicolumn{4}{|c|}{ Smoking } & \multicolumn{4}{|c|}{ Drinking } & \multicolumn{4}{|c|}{ Regular exercise } \\
\hline & $\beta$ value & S.E. & OR & $\mathrm{p}$ value & $\beta$ value & S.E. & OR & $\mathrm{p}$ value & $\beta$ value & S.E. & OR & $\mathrm{p}$ value \\
\hline US/AS ratio & 0.014 & 0.006 & 1.015 & 0.010 & 0.007 & 0.004 & 1.007 & 0.078 & 0.012 & 0.014 & 1.012 & 0.372 \\
\hline $\mathrm{BS} / \mathrm{AS}$ ratio & 0.005 & 0.007 & 1.005 & 0.458 & 0.001 & 0.001 & 1.000 & 0.710 & 0.000 & 0.001 & 1.000 & 0.657 \\
\hline US/BS ratio & 0.002 & 0.003 & 1.002 & 0.376 & 0.004 & 0.003 & 1.004 & 0.139 & 0.004 & 0.003 & 1.004 & 0.182 \\
\hline MA & 1.414 & 0.706 & 4.111 & 0.045 & -0.243 & 0.553 & 0.784 & 0.660 & 0.112 & 1.765 & 1.118 & 0.950 \\
\hline PGA & 4.057 & 1.784 & 5.778 & 0.023 & -1.708 & 1.694 & 0.181 & 0.313 & 0.076 & 1.694 & 1.079 & 0.964 \\
\hline MA/US ratio & 4.468 & 1.864 & 8.716 & 0.017 & 0.754 & 0.577 & 2.126 & 0.191 & -0.162 & 0.280 & 0.850 & 0.562 \\
\hline PGA/US ratio & 3.325 & 1.730 & 2.779 & 0.055 & 0.165 & 0.365 & 1.179 & 0.652 & -2.551 & 1.283 & 0.078 & 0.047 \\
\hline
\end{tabular}

US, urinary styrene; BS, blood styrene; MA, mandelic acid; PGA, phenyloxylic acid; S.E., standard error; OR, odds ratio. 
exercise can modulate the levels of urinary styrene metabolites such as MA and PGA after occupational exposure to styrene. The results of this study showed that neither genetic polymorphism of the styrene-metabolizing enzymes CYP2E1, GSTM1, or GSTT1 nor the lifestyle habits or serum biochemistry significantly affected styrene metabolism. Furthermore, no significant correlation was observed between the parameters of anthropometric and styrene metabolism. The exposure level of styrene was $25.2 \pm 38.8$ ppm; the styrene levels in blood and urine were $828.9 \pm$ $1,183.0$ and $311.4 \pm 549.3 \mathrm{mg} / \mathrm{L}$, respectively; and urinary MA and PGA levels were $0.36 \pm 0.42$ and $0.53 \pm 0.55 \mathrm{~g} / \mathrm{g}$ creatinine, respectively (Table 1). Instead, in this study, we found that albumin was significantly correlated with BS/ AS, US/AS, US/BS, and the metabolite ratio (Table 5). Human body fluid such as plasma and serum contains biochemical products that can function as homeostasis controls. In addition, plasma and serum contain numerous proteins involved in inflammation and immunity, lipid metabolism, coagulation, and small molecule transport (23). Among the serum proteins, human serum albumin is the most abundant, and it has fundamental roles as a regulator of $\mathrm{pH}$ and in the transport and distribution of endogenous and exogenous substances (24). Thus, our results, which showed significantly correlation between serum albumin and styrene levels in the blood and urine along with levels of its metabolites, are thought to result from the role of albumin in styrene transport. When living organisms are exposed to environmental xenobiotics including drugs, they are able to produce enzymes specific to the detoxification process, and thereby to metabolize and excrete the metabolites from their bodies. The chemicals absorbed by the human body are converted into reactive electrophilic intermediates by phase I enzymes (CYP); subsequently, the phase II enzymes (GST-linked enzymes) detoxify these activated intermediates by conjugation reactions. However, the activities of these enzymes carry genetic susceptibilities. Carbonari et al. (25) reported that a lower excretion level of MA+ PGA was detected for exposed subjects carrying both the heterozygous alleles CYP2E $1 * 5 \mathrm{~B}$ and CYP2E1*6 in comparison to the wild-type homozygous; however, no difference in the urinary metabolites of styrene was observed for GSTM1 and GSTT1 genotypes. Ma et al. (15) also reported that no significant difference in the excretion levels of urinary metabolites was observed between active and null types of GSTM1 and GSTTI. In this study, the US/BS ratio was significantly higher in individuals carrying the GSTM1 positive variant than those with the GSTM1 null variant, and the US/MA ratio was higher in men with CYP2E1*5 homozygous alleles than in those with heterozygous alleles, although this was not significant. This result suggests that the genetic polymorphisms CYP2E1*5 and null/active GSTM1 were associated with the detoxification of styrene. In contrast, previous reports found that neither the genotypes of xenobiotic metabolizing enzymes nor lifestyle habits (smoking, drinking, and exercise) significantly affected the metabolism of xenobiotic including styrene $(15,18)$. Therefore, multiple logistic regression analysis was performed with the genetic polymorphisms of styrene-metabolizing enzymes and these lifestyle habits as dependent variables and styrene metabolites as independent variables. The results showed that the MA/ US ratio was significantly associated with the CYP2E $1 * 5$ genotype and that the US/BS ratio was associated with GSTM1. In addition, a smoking habit was significantly associated with the US/AS ratio, urinary MA and PGA levels, and the MA/US ratio, and regular exercise was significantly associated with the PGA/US ratio; however, a drinking habit was not associated with excretion levels of styrene metabolites. Our results suggest that the styrenemetabolizing enzymes CYP2E1, GSTM1, and GSTT1 are directly involved in specific steps of the styrene metabolic process and that lifestyle behaviors such as smoking, drinking, and exercise affect the expression and induction of the styrene-metabolizing enzymes and the regulation of homeostasis, and thereby are ultimately thought to play a mediating role in the metabolism of styrene.

\section{ACKNOWLEDGMENTS}

This study was supported by the Intramural Research Fund of the Occupational Safety and Health Research Institute (OSHRI) of Korea.

\section{REFERENCES}

1. International Programme on Chemical Safety (IPCS). (1983) Styrene. Environmental Health Criteria 26. World Health Organization, Geneva, pp. 20-50.

2. Ministry of Employment and Labor (MoEL). (2013) 2013 Annual report for the health examination of workers. Ministry of Employment and Labor.

3. Watabe, T., Ozawa, N. and Yoshkawa, K. (1981) Stereochemistry in the oxidative metabolism of styrene by hepatic microsomes. Biochem. Pharmacol., 30, 1695-1698.

4. Ohtsuji, H. and Ikeda, M. (1971) The metabolism of styrene in rat and the stimulatory effect of phenobarbital. Toxicol. Appl. Pharmacol., 18, 321-328.

5. Laffon, B., Pásaro, E. and Méndez, J. (2001) Effects of styrene-7,8-oxide over p53, p21, bcl-2 and bax expression in human lymphocyte cultures. Mutagenesis, 16, 127-132.

6. Chakrabarti, S.K. (2000) Altered regulation of dopaminergic activity and impairment in motor function in rats after subchronic exposure to styrene. Pharmacol. Biochem. Behav., 66, 523-532.

7. Husain, R., Srivastava, S.P., Mushtaq, M. and Seth, P.K. (1980) Effect of styrene on levels of serotonin, noradrenalin, dopamine and activity of acetyl cholinesterase and monoamine oxidase in rat brain. Toxicol. Lett., 7, 47-50.

8. Sumner, S.J. and Fennell, T.R. (1994) Review of metabolic 
fate of styrene. Crit. Rev. Toxicol., 24, S11-33.

9. American Conference of Government Industrial Hygienists (ACGIH). (2000) Threshold limit values (TLVs) for chemical substances and physical agents and biological exposure indices (BEIs). ACGIH, Cincinnati, OH.

10. Wenker, M.A., Kezić, S., Monster, A.C. and de Wolff, F.A. (2001) Metabolic capacity and interindividual variation in toxicokinetics of styrene in volunteers. Hum. Exp. Toxicol., 20, 221-228.

11. De Palma, G., Manini, P., Mozzoni, P., Andreoli, R., Bergamaschi, E., Cavazzini, S., Franchini, I. and Mutti, A. (2001) Pholimorphism of xenobiotic-metabolizing enzymes and excretion of styrene-specific mercapturic acids. Chem. Res. Toxicol., 14, 1393-1400.

12. Haufroid, V., Buchet, J.P., Gardinal, S., Ghittori, S., Imbriani, M., Hirvonen, A. and Lison, D. (2001) Importance of genetic polymorphism in interpreting drug-metabolizing enzymes for the interpretation of biomarkers of exposure of styrene. Biomarkers, 6, 236-249.

13. Haufroid, V., Jakubowski, M., Janasik, B., Ligocka, D., Buchet, J.P., Bergamaschi, E., Manini, P., Mutti, A., Ghittori, S., Arand, M., Hangen, N., Oesch, F., Hirvonen, A. and Lison, D. (2002) Interest of genotyping and phenotyping of drugmetabolizing enzymes for the interpretation of biological monitoring of exposure to styrene. Pharmacogenetics, 12, 691-702.

14. De Palma, G., Mozzoni, P., Scotti, E., Manini, P., Andreoli, R., Naccarati, A., Mercati, F., Migliore, L. and Mutti, A. (2003) [Genetic polymorphism of biotransforming enzymes and genotoxic effects of styrene]. G. Ital. Med. Lav. Ergon., 25 Suppl 3, 63-64.

15. Ma, M., Umemura, T., Mori, Y., Gong. Y., Saijo, Y., Sato, F., Kawai, T. and Kishi, R. (2005) Influence of genetic polymorphisms of styrene-metabolizing enzymes and smoking habits on levels of urinary metabolites after occupational exposure to styrene. Toxicol. Lett., 160, 84-91.

16. Conccini, T., Di Nucci, A., Tonini, M., Maestri, L., Costa, L.G., Liuzzi, M. and Manzo, L. (1996) Effects of ethanol administration on cerebral non-protein sulfhydryl content in rats exposed to styrene vapour. Toxicology, 106, 115-122.

17. NIOSH. (1996) NIOSH manual of analytical methods (4th edition). Method 1501, U.S. Department of Health and Human Services, Cincinnati.

18. Kim, K.W., Won, Y.L. and Ko, K.S. (2015) Ethnic differences in the metabolism of toluene: coparisons between Korean and foreign workers exposed to toluene. Toxicol. Res., 31, 25-32.

19. de Carvalho, D., Lanchote, V.L., Bonato, P.S., Queiroz, R.H., Santos, A.C. and Dreossi, S.A. (1991) A new derivatization procedure for the analysis of hippuric acid and methyl hippuric acid by gaschromatography. Int. Arch. Occup. Environ. Health, 63, 33-37.

20. Shaikh, R.S., Amir, M., Masood, A.I., Sohail, A., Athar, H.U., Siraj, S., Ali, M. and Anjam, M.S. (2010) Frequency distribution of GSTM1 and GSTT1 null allele in Parkistani population and risk of disease incidence. Environ. Toxicol. Pharmacol., 30, 76-79.

21. Cai, L., Zheng, Z.L. and Zhang, Z.F. (2005) Cytochrome p4502E1 polymorphisms and the risk of gastric cardiac cancer. World J. Gastroenterol., 11, 1867-1871.

22. Prieto-Castelló, M.J., Cardona, A., Marhuenda, D., Roei, J.M. and Corno, A. (2010) Use of the CYP2E1 genotype and phenotype for the biological monitoring of occupational exposure to styrene. Toxicol. Lett., 192, 34-39.

23. Kim, M.R. and Kim, C.W. (2007) Human blood plasma preparation for tow-dimensional gel electrophoresis. J. Chromatogr. B Anal. Technol. Biomed. Life Sci., 849, 203-210.

24. Bern, M., Sand, K.M., Nilson, J., Sandlie, I. and Andersen, J.T. (2015) The role of albumin receptors in regulation of albumin homeostasis: Implications for drug delivery. J. Controlled Release, 211, 144-162.

25. Carbonari, D., Mansi, A., Proietto, A.R., Paci, E., Bonanni, R.C., Gherardi, M., Gatto, M.P., Sisto, R. and Tranfo, G. (2015) Influence of genetic polymorphisms of styrene-metabolizing enzymes on the levels of urinary biomarkers of styrene exposure. Toxicol. Lett., 233, 156-162. 